\title{
FORMAÇÃO DE RECURSOS HUMANOS NA ÁREA DA SAÚDE DO IDOSO ${ }^{1}$
}

Maria José D’Elboux Diogo ${ }^{2}$

Diogo MJD’E. Formação de recursos humanos na área da saúde do idoso. Rev Latino-am Enfermagem 2004 março-abril; 12(2):280-2.

O texto aborda as questões vinculadas à formação de recursos humanos especializados e informais na área da saúde do idoso, com base na Política Nacional de Saúde do Idoso. Aponta para as dificuldades na formação desses recursos e as recomendações da Segunda Assembléia Mundial sobre o Envelhecimento.

DESCRITORES: recursos humanos em saúde; geriatria

\section{HUMAN RESOURCE FORMATION IN ELDERLY'S HEALTH}

This paper deals with issues related to specialized and informal human resource training programs in the area of elderly's health, based on the National Elderly's Health Policy. It points out the obstacles and recommendations made by the Second World Assembly on Aging.

DESCRIPTORS: human resources in health; geriatrics

\section{LA FORMACIÓN DE LOS RECURSOS HUMANOS EN LA SALUD DEL ANCIANO}

El texto trata los aspectos relacionados con la formación de los recursos humanos especializados e informales en la salud del anciano, en el contexto de la Política Nacional de Salud del Anciano. Destaca las dificultades en la formación de estos recursos y las recomendaciones de la Segunda Asamblea Mundial sobre el Envejecimiento.

\footnotetext{
${ }^{1}$ Texto produzido com base na palestra proferida no $3^{\circ}$ Congresso Paulista de Geriatria e Gerontologia, Santos, 29 de maio a $1^{\circ}$ de junho de 2003 ;

${ }^{2}$ Enfermeira, Livre-Docente, Professor Associado da Faculdade de Ciências Médicas da Universidade Estadual de Campinas, e-mail: mariadio@uol.com.br
} 
INTRODUÇÃO

$\boldsymbol{A}$ formação de recursos humanos em gerontologia diz respeito diretamente à qualidade de vida na velhice, uma vez que essa decorre da relação entre as condições físicas, competências comportamentais do idoso e as condições ambientais, mantendo relação direta com o bem-estar percebido. Assim, o idoso que encontra um ambiente (recursos físicos e pessoais) responsivo e adequado ao seu desempenho funcional e competência comportamental sente-se adaptado e apresenta bem-estar subjetivo positivo ${ }^{(1)}$.

Ao realizarmos um recorte desse cenário, o presente texto tem o objetivo de discorrer sobre a formação de recursos humanos na área da saúde do idoso, tendo como referência a Política Nacional de Saúde do Idoso (PNSI). Entre as diretrizes para o alcance do propósito da PNSI, destacamos aqui a capacitação de recursos humanos especializados (profissionais) e o apoio ao desenvolvimento de cuidados informais ${ }^{(2)}$.

\section{RECURSOS HUMANOS ESPECIALIZADOS}

Para o desenvolvimento e a capacitação de recursos humanos especializados, a PNSI conta com a participação do Ministério da Educação e das Instituições de Ensino Superior (IES), por intermédio dos Centros Colaboradores de Geriatria e Gerontologia. Embora esses órgãos tenham a função específica de capacitar os profissionais para prestar a devida cooperação técnica demandada pelos diferentes níveis de gestão, a formação dos profissionais na área da saúde do idoso, na realidade, se depara com vários obstáculos que comprometem a competência e a qualidade da assistência prestada a essa clientela. A escassez de conhecimento gerontogeriátrico dos profissionais da saúde, a ausência de sintonia da maioria das IES brasileiras com o atual processo de transição demográfica e suas conseqüências médicosociais, a escassez de conteúdo gerontogeriátrico nos currículos, a falta de campos específicos para a prática, além da inexperiência do corpo docente, são algumas das limitações presentes nos cursos de graduação da área da saúde ${ }^{(3-4)}$.

Especificamente para o curso de Enfermagem, a Organização Panamericana da Saúde (OPAS) recomenda: que não sejam oferecidos conteúdos gerontogeriátricos parciais integrados a outras disciplinas, para não se correr o risco de diluir ou reduzi-los ao longo da grade curricular, bem como que os conteúdos sobre o cuidado ao idoso sadio preceda os referentes ao cuidado do idoso enfermo ou institucionalizado, permitindo ao estudante visualizar essa etapa da vida como um período em que o ser humano sofre limitações da idade, mas que também pode desfrutar de uma fase de bem-estar e desenvolvimento ${ }^{(4-5)}$.

Em Viena, de 23 a 26 de abril de 2001, a Terceira Reunião do Comitê Técnico para a Segunda Assembléia Mundial sobre o Envelhecimento (ocorrida em Madrid, de 8 a 12 de abril de 2002) destacou que, entre os jovens, os aspectos negativos da velhice ainda se sobrepõem aos positivos e que são raros os cursos que abordam os aspectos positivos, perpetuando mitos e estereótipos relacionados à velhice e à pessoa idosa. A formação de recursos humanos em geriatria e gerontologia ainda ocorre de maneira não-formal, por meio de eventos de curta duração, normalmente promovidos por sociedades científicas, institutos e organizações não circunscritas à formação convencional. Contudo, são os cursos de extensão universitária e de pós-graduação lato sensu (especialização) e stricto sensu (mestrado e doutorado) os responsáveis pela formação e capacitação de pesquisadores e de profissionais que atuam com idosos ${ }^{(6-}$ 7).

Entre as recomendações traçadas nessa reunião, destacam-se: a expansão da educação profissional em gerontologia e geriatria; a inclusão de treinamento multidisciplinar; a formação básica e especializada sobre a saúde do idoso; a promoção de programas de educação contínua em saúde, bem-estar e cuidado de pessoas idosas para profissionais da área da saúde, da assistência social e cuidadores; o estímulo para o aumento de estudantes na área e a promoção de programas de treinamento em gerontologia e geriatria, em países em desenvolvimento, através da cooperação bilateral e multilateral internacional ${ }^{(6)}$.

As escolas de enfermagem do Brasil, a que tudo indica, apresentam escasso número de docentes envolvidos em programas de mestrado ou doutorado, desenvolvendo pesquisas ou estudando enfermagem gerontológica. A maioria dos professores dos cursos de graduação em Enfermagem ensina conteúdos sobre esse tema através da sua experiência ou conhecimentos ou, ainda, por meio de auto-estudo e educação contínua. Dados de pesquisa apontam que $87,73 \%$ dos cursos de 
graduação em enfermagem, de alguma forma, abordam conteúdos relacionados a essa temática em seus currículos, porém, de modo muito heterogêneo na forma de inserção que utilizam, na carga horária e nos temas abordados $^{(5)}$.

Em termos de produção científica, especificamente no campo da gerontologia, somente a partir da década de 70 é possível observar certo incremento nas diversas áreas de conhecimento, com gradativa expressão a partir da década 80 e especialmente em 90 , com a criação dos primeiros cursos de pós-graduação em gerontologia e geriatria ${ }^{(7)}$.

\section{RECURSOS HUMANOS INFORMAIS}

Com relação ao apoio ao desenvolvimento de cuidados informais, a PNSI prevê parceria entre os profissionais da saúde e as pessoas próximas aos idosos, responsáveis pelos cuidados diretos necessários, denominados cuidadores. Essa parceria se configura numa estratégia mais atual e menos onerosa para manter e promover a melhoria da capacidade funcional dos idosos dependentes ${ }^{(2)}$.

A falta de rede de suporte mais efetiva na área social e de saúde para o cuidado são alguns fatores desencadeantes do estresse nos cuidadores de idosos.

\section{REFERÊNCIAS BIBLIOGRÁFICAS}

1. Lawton MP. A multidimensional view of quality of life in frail elders. In: Birren JE, Lubben JE, Rowe JC, Deutchman DE, editors. The concept and measurement of quality of life in the frail elderly. San Diego: Academic Press; 1991. p.3-27.

2. Portaria $n^{\circ}$ 1395. Dispõe sobre a Política Nacional de Saúde do Idoso. Diário Oficial da União 199913 de dez: Seção 1, p. 20-4.

3. Cabrera M, Almeida JR de, Turini B, Martin G, Domiciano SP. Ensino de geriatria através do aprendizado baseado em problemas: experiência da Universidade Estadual de Londrina, PR. Gerontologia 2000 abril-junho; 8(2):56-62.

4. Camacho ACLF. A gerontologia e a interdisciplinaridade: aspectos relevantes para a enfermagem. Rev Latino-am Enfermagem 2002 março-abril; 10(2):229-33.

5. Diogo MJD'E; Duarte YAO. O envelhecimento e o idoso no ensino de graduação em enfermagem no Brasil: do panorama atual à uma proposta de conteúdo programático. Rev Esc Enfermagem USP 1999 julho/ago; 33(4):370-6.
Embora, no Brasil, em 1999, tenha ocorrido o início da operacionalização do projeto de Pólos de Capacitação e Pesquisa na área de geriatria e gerontologia, esse não teve continuidade, além do que são escassos e regionais os programas de suporte direcionados especificamente aos recursos pessoais informais.

$N$ a realidade, o cuidador nem sempre é único. $O$ estudo com famílias japonesas e brasileiras apontou para a importante questão da formação da rede de cuidadores, construída no decorrer das interações ${ }^{(8)}$. Cada situação é única e, portanto, não basta o conhecimento técnicocientífico advindo somente da capacitação de cuidadores. É necessário também o olhar direcionado aos valores, crenças e atitudes que permeiam as relações e o contexto domiciliar ou familiar em diferentes situações ${ }^{(8-10)}$.

\section{CONSIDERAÇÕES FINAIS}

Ao aceitarmos a concepção de que o envelhecimento compreende múltiplas dimensões destacase: a importância de se pensar currículos de cursos de graduação que contemplem disciplinas específicas sobre gerontologia e geriatria, a necessidade do preparo formal dos cuidadores familiares de idosos e do estímulo à formação de redes de cuidadores familiares, visto que já o fazem espontaneamente.

6. The Second World Assembly on Ageing 2002 (Espanha). The Third Meeting of the Technical Committee for the Second World Assembly on Ageing. [on line] [acesso em 10/05/2003]. Disponível em: URL: www.un.org/esa/socdev/ageing/waa/ 02tcmeet3.htm

7. Sá JLM. Gerontologia e interdisciplinaridade: fundamentos epistemológicos. In: Neri AL, Debert GG, organizadoras. Velhice e Sociedade. São Paulo (SP): Papirus; 1999. p.22332.

8. Santos SMA dos. A construção do cuidador familiar de pessoas com demência: um estudo em famílias japonesas e brasileiras. [tese]. Campinas (SP): Faculdade de Educação/ UNICAMP; 2003.

9. Sommerhalder C. Significados associados à tarefa de cuidar de idosos de alta dependência no contexto familiar. [dissertação]. Campinas (SP): Faculdade de Educação/ UNICAMP; 2001.

10. Diogo MJD'E, Duarte YAO. Cuidados em domicílio: conceitos e práticas. In: Freitas EV, Py L, Neri AL, Cançado FAX, Gorzoni ML, Rocha SM, organizadoras. Tratado de geriatria e gerontologia. Rio de Janeiro (RJ): Guanabara Koogan; 2002. p.762-7. 